\title{
3D Finite Element Analysis of Pile Behavior Inside the Deep Excavation in Soft Soil
}

\author{
Nghia Trong Le, \\ Lecturer, PhD. \\ Ho Chi Minh City University of Technology - Vietnam \\ National University Ho Chi Minh City \\ 268 Ly Thuong Kiet Street, District 10, \\ Ho Chi Minh City, Viet Nam.
}

\author{
Tuan Anh Nguyen, \\ Lecturer, $\mathrm{PhD}$. \\ Ho Chi Minh City University of Transport \\ 2 Vo Oanh Street, Binh Thanh District, \\ Ho Chi Minh City, Viet Nam.
}

\begin{abstract}
A large excavation was carried out in the thick soft soil layer to construct the pile cap foundation and the basement floor for the 15 stories-building in Ho Chi Minh City. The soil profile consists of a 25-meter-thick of very soft clay with SPT value of zero laid on an 8.5-meter-thick of soft clay with SPT value of 3 and laid on a 13.9-meter-thick of medium dense fine sand with SPT value of 17 . The excavation was supported by the system of 6-meter-depth SP - IV steel sheet piles with the tied-back rods on the top of the wall to the $6 \mathrm{~m} \mathrm{H}$ steel piles installed behind the wall. Before the excavation, the spun PHC pile with $600 \mathrm{~mm}$ diameter and $100 \mathrm{~mm}$ thick was installed to support the superstructure. As excavation to 3.8 meter depth, four piles with the distance $4.55 \mathrm{~m}, 7.15 \mathrm{~m}, 10.65 \mathrm{~m}$ and $13.25 \mathrm{~m}$ from the wall had the top pile displacement $63.5 \mathrm{~cm}, 38.86 \mathrm{~cm}$, $19.5 \mathrm{~cm}$ and $11.4 \mathrm{~cm}$, respectively. Furthermore, all these piles were determined to be cracked by using the PIT test. Base on the collected data, back analysis was carried out by using PLAXIS 3D Foundation with Hardening-Soil soil model to determine the response of these piles during excavation. In the results, the maximum bending moment of these piles was over its ultimate value, thereby, we can analyze the reason piles group in this building was failure and use the parameters in PLAXIS for expanding the analysis to other situations.
\end{abstract}

Keywords-Failure, steel sheet piles, excavation, soft clay, bending moment.

\section{INTRODUTION}

In Ho Chi Minh City, a large number of high buildings with the basement floors were constructed to supply the living houses and working offices. Ho Chi Minh City lies on a complex stratum with the soft clay layer somewhere is thicker than 30 meters. Therefore, a lot of problems were happened during the excavation process to build the basement floors for the high building. Some works have taken place the failure of inside existing piles due to the deep excavation.

In 2007, all the installed piles to support the superstructure of Thao Dien building in District 2 Ho Chi Minh City were tilted during the basement excavation. A 13 stories building in District 7 has the PHC pile top move 0.6 meter when basement construction was carried out [9].

In similarly, the silo cement in Hiep Phuoc industry zone used the spun PHC pile with pile length from 33 to 35 meter through the thick soft soil layer had about 80 percent of piles under the silo were tilted in the same direction. A mumber of 2664 piles among of 7474 piles of the water treatment station in Binh Chanh District had the top horizontal displacement in the excavation process [9].

In 2011, a 15-story building in district 8 built on the ground with $25 \mathrm{~m}$ deep of soft clay, the piles near the steel sheet pile wall was tilt and beak out during the pit foundation excavation. The maximum top pile horizontal displacement was up to 0.6 meter.

Analysing the failure of pile inside deep foundation pit in soft soil is a considered problem. The deep excavation in soft soil is very complicated; the lateral displacement of soft soil produces the passive pressure on pile. It causes the pile movement and bending moment greater than capacity moment of the pile; therefore, the piles are damage.

According to Kok S.T (2009), there are three common methods for researching about the effect of excavation to the nearby pile foundation: The Finite element, the centrifuge test and the field test $[1,4]$. Poulos \& Chen (1996) did analysis by using of the finite-element method analyze the response of piles due to unsupported excavation induced lateral soil movement in clay [2]. This method was also used in back analyzing to the responses of pile subjected to horizontal soil movements in clay, and many researchers use Finite element method for their own studies. Finite element method is easy to progress, and the result less fluctuate and appropriate with reality. However, the result from this analysis is affected by many factors that are required experience and understanding of not only geotechnical issue but also solutions and software.

Recent efforts in centrifuge modeling of passive piles adjacent to unbraced excavation was done by Leung, Ong. Initially, Leung (2000) presented the results of centrifuge tests of an adjacent single pile behind an unstrutted stable and failed wall of a deep excavation in dense sand. The research also investigates the influence of head piles fixity for behind the stable wall, the pile head deflection and maximum bending moment for the free-headed pile decreases exponentially with increasing distance from the excavation. Subsequently, Leung (2003) extended the centrifuge test to pile groups, incorporating the effects of interaction factors between the piles with different head fixities. Following Leung (2000), further investigation was done for single pile behind stable wall (Ong, 2006) and instable wall (Leung, $2006)$ in clay $[5,6,7]$.

Finno et al (1991) and Goh et al (2003) executed the field test. According to Goh (2003), used movement measurer for soil horizontal displacement in actual field and examine the behavior of an existing pile due to nearby excavation of a 
$16 \mathrm{~m}$ deep excavation, the results of movement and bending moment of piles between observation and predicted by BCPILE program was quite similar [3].

Considering the influence of deep excavation to piles inside the foundation pit, Thasnanipan (1998) presented four case histories of pile damage associated with excavation works in Bangkok soft clay [8]. The failures were examized by high strain dynamic load test and also modeled by a twodimensional finite element to predict the response of the piles. Since then, finding a correlation between the location of cracks and bending moment in the pile exceeds the allowed bending moment. Besides, Kok (2009) presents a case study in West Malaysia for passive piles failure in very soft marine clay in open excavation due to soil displacement. Kok (2009) used PLAXIS 3D Foundation software for back-analysis, Hardening soil model was used in analysis. The analytical result of excavation phases was compared with the cracking moment resistance of piles, Kok showed that $70 \%$ of modeled piles which have axial bending moment caused by pit construction exceed the piles's cracking moment and the result was all the pile are cracked. The cracking position occurred in adjacent layers between weak clay and hard clay.

Nowadays, a lot of deep excavation have trouble in the construction process due to the large displacement of soft soil causing excess load on the pile bearing capacity and make the failure of piles. Therefore, analyzing the failure reasons as well as finding suitable alternatives for construction excavation without affecting piles in deep pits is an issue needed to study. Owing to that reason, this paper analyzed the horizontal movement of piles, the largest bending moment in pile of deep excavation construction in soft soil in Ho Chi Minh City, district 8 by Finite element method with Hardening soil model. The analysis result will be compared with the observation data to show the soil model and data appropriate for design and apply for analyse for the same constructions.

\section{ANALYSE THE FAILURE OF PILES INSIDE EXCAVATION}

\section{A. Project Description}

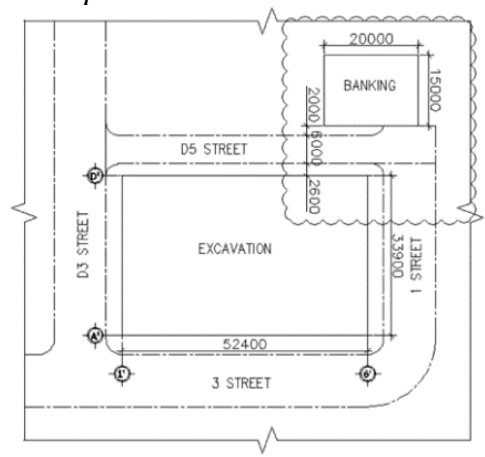

Fig. 1. Excavation construction general plan

The residence building in District 8 - Ho Chi Minh City have 15 upper ground floors and 1 basement floor sing the prestressed reinforced concrete spun pile foundation to resist superstructure. The foundation pit is $52.4 \mathrm{~m}$ long and $33.9 \mathrm{~m}$ wide and $3.8 \mathrm{~m}$ deep was constructed by braced excavation method. The 6-meter-long SP - IV steel sheet piles was installed to retain the excavation during the basement construction. The main construction includes 4 main steps is shown on the figs. (1-5).

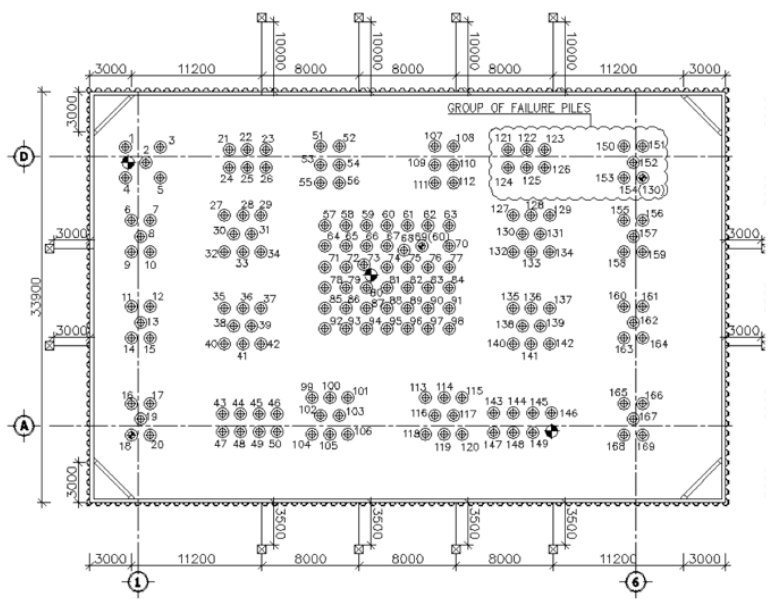

Fig. 2. Foundation pit construction plan

Step 1: Construct the prestress spun concrete piles 600 diameter (includes 3 section, $12 \mathrm{~m}$ long per section)

Step 2: Construct the steel sheet pile wall.

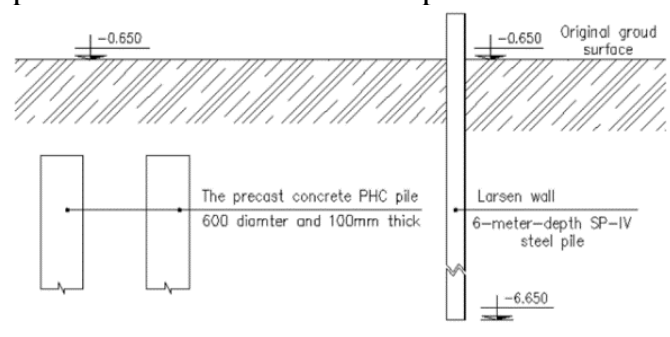

Fig. 3. Plan of after construct piles and steel sheet pile wall Step 3: Excavate to $1.8 \mathrm{~m}$

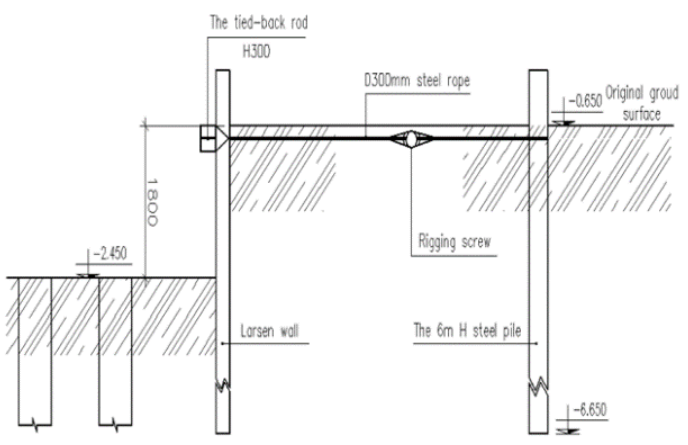

Fig. 4.. Excavate to $1.8 \mathrm{~m}$ deep

Step 4: Excavate to $3.8 \mathrm{~m}$ deep at the bottom of foundation pit (compared with the natural ground level).

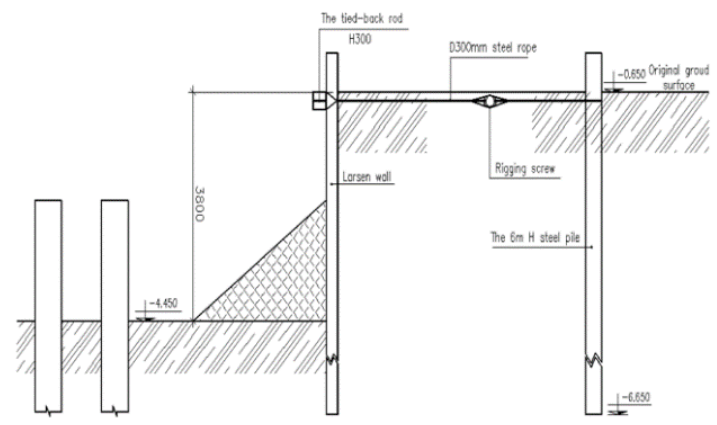

Fig. 5. Excavate to $3.8 \mathrm{~m}$ deep (compared with natural ground level) 


\section{B. Geological characteristics}

Geological characteristics and parameters of soil layer are presented in Figure 6, the distance between ground surface and underground water level is $1.5 \mathrm{~m}$. Based on geological records survey to identify the soil model parameters for the deep excavation stimulated in Plaxis 3D. The shear strength parameters $c^{\prime}$ and $\varphi^{\prime}$ are determined from triaxial CU test. Soil modulus in Hardening Soil model is defined as:

Clay layers module $\mathrm{E}_{\mathrm{oed}}{ }^{\mathrm{ref}}=\mathrm{E}_{50}{ }^{\mathrm{ref}}=\alpha \mathrm{s}_{\mathrm{u}}, \mathrm{s}_{\mathrm{u}}$ is undrained shear strength of soft soil.

The third layer: Silt sand from dense to loose, module parameter $\mathrm{E}$ is chosen base on the correlation module $\mathrm{E}$ table of Bowles, 1988 or Malcolm Puller, 2003. The unloading reloading module is selected as $\mathrm{E}_{\mathrm{ur}}{ }^{\mathrm{ref}}=3 \mathrm{E}_{50}{ }^{\mathrm{ref}}$

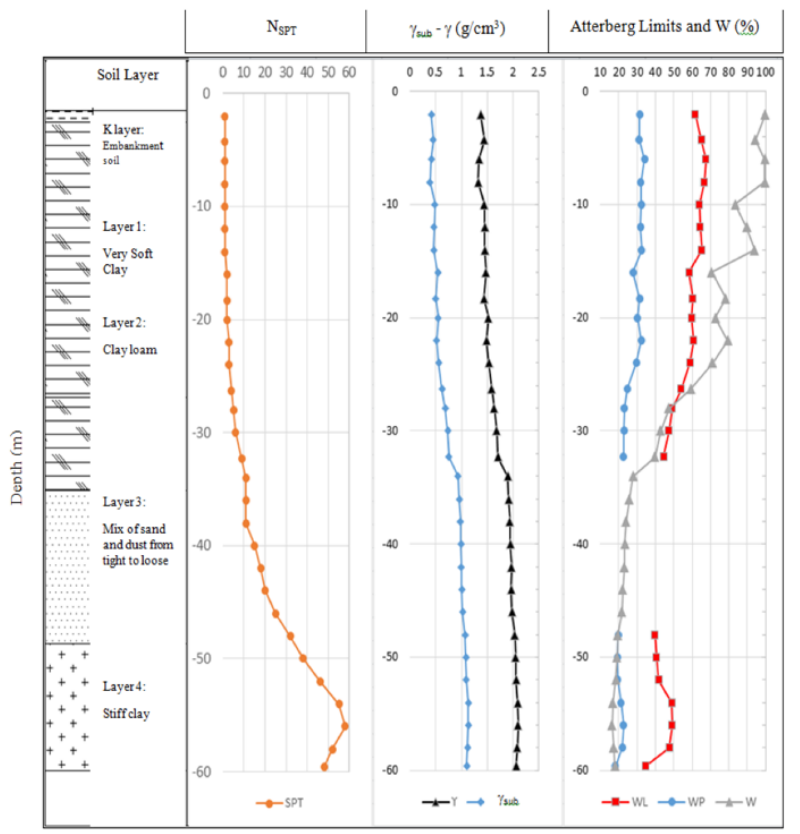

Fig. 6. Representation of the typical geological parameter of building

TABLE 1. SOIL PARAMETERS IN PLAXIS 3D FOUNDATION

\begin{tabular}{|c|c|c|c|c|c|c|}
\hline $\begin{array}{c}\text { Layer } \\
\text { Paka } \\
\text { meter }\end{array}$ & Unit & $\begin{array}{c}\text { Fill } \\
\text { layer } \\
\text { MC }\end{array}$ & $\begin{array}{c}\text { Layer 1 } \\
\text { HS/ } \\
\text { Undrain } \\
\text { ed }\end{array}$ & $\begin{array}{c}\text { Layer 2 } \\
\text { HS/ } \\
\text { Undrain } \\
\text { ed }\end{array}$ & $\begin{array}{c}\text { Layer 3 } \\
\text { HS/ } \\
\text { Drained }\end{array}$ & $\begin{array}{c}\text { Layer 4 } \\
\text { HS/ } \\
\text { Undrained }\end{array}$ \\
\hline$\gamma_{\text {unsat }}$ & $\mathrm{kN} / \mathrm{m}^{3}$ & 18 & 14.5 & 16.6 & 19.5 & 20.6 \\
\hline$\gamma_{\text {sat }}$ & $\mathrm{kN} / \mathrm{m}^{3}$ & 18 & 14.8 & 17.4 & 19.9 & 21 \\
\hline $\mathrm{k}_{\mathrm{x}}$ & $\mathrm{m} / \mathrm{day}$ & $8.64 \mathrm{E}-2$ & $8.64 \mathrm{E}-6$ & $8.64 \mathrm{E}-5$ & $8.64 \mathrm{E}-3$ & $8.64 \mathrm{E}-6$ \\
\hline $\mathrm{k}_{\mathrm{y}}$ & $\mathrm{m} /$ day & $8.64 \mathrm{E}-2$ & $8.64 \mathrm{E}-6$ & $8.64 \mathrm{E}-5$ & $8.64 \mathrm{E}-3$ & $8.64 \mathrm{E}-6$ \\
\hline $\mathrm{c}^{\prime}$ & $\mathrm{kN} / \mathrm{m}^{2}$ & 0.1 & 5.6 & 9.2 & 3.1 & 20.9 \\
\hline$\varphi^{\prime}$ & Degree & 28000 & $17000^{\prime}$ & $25000^{\prime}$ & $29000^{\prime}$ & $28000^{\prime}$ \\
\hline$\psi$ & Degree & 0 & 0 & 0 & 0 & 0 \\
\hline$v_{\text {ur }}$ & - & 0.25 & 0.35 & 0.35 & 0.25 & 0.3 \\
\hline $\mathrm{E}_{50} \mathrm{r}^{\text {ef }}$ & $\mathrm{kN} / \mathrm{m}^{2}$ & - & 1200 & 3500 & 15000 & 30000 \\
\hline $\mathrm{E}_{\text {of }}$ ref & $\mathrm{kN} / \mathrm{m}^{2}$ & - & 1200 & 3500 & 15000 & 30000 \\
\hline $\mathrm{E}_{\text {rr }}$ ref & $\mathrm{kN} / \mathrm{m}^{2}$ & - & 3600 & 10500 & 45000 & 90000 \\
\hline $\mathrm{R}_{\text {inter }}$ & 1 & 1 & 1 & 1 & 1 & 1 \\
\hline $\mathrm{m}$ & - & 1 & 0.9 & 0.9 & 0.75 & 0.9 \\
\hline
\end{tabular}

The embankment soil layer has $\mathrm{E}^{\mathrm{ref}}=10000 \mathrm{kN} / \mathrm{m}^{2}$.

\section{Analysis model}

Analysis of the influence of the pile in the pit with the actual case, the sub-loading of construction machine and near by building are taken $10 \mathrm{kN} / \mathrm{m}^{2}$ and away from outer edge of Larsen wall $2.6 \mathrm{~m}$, located on natural ground surface. In addition, during the construction, soil is being moved and collected far from excavation about $11 \mathrm{~m}$ in the area of 200 $\mathrm{m}^{2}$ and $4 \mathrm{~m}$ in height so the author decide $70 \mathrm{kN} / \mathrm{m}^{2}$. The distant between underground water level and natural ground surface is $1.5 \mathrm{~m}$ (Fig. 7-9).

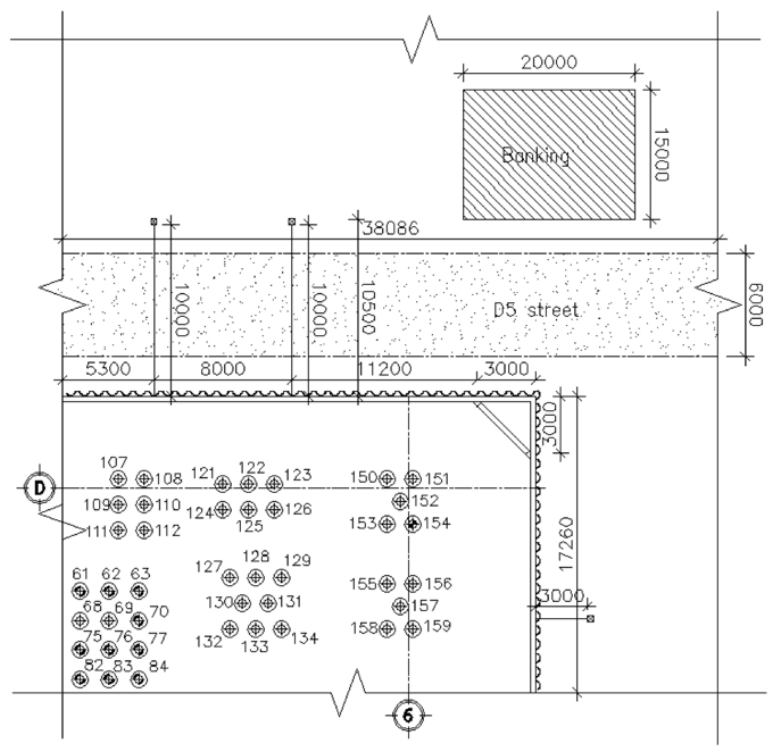

Fig. 7. Construction pland and embankment position

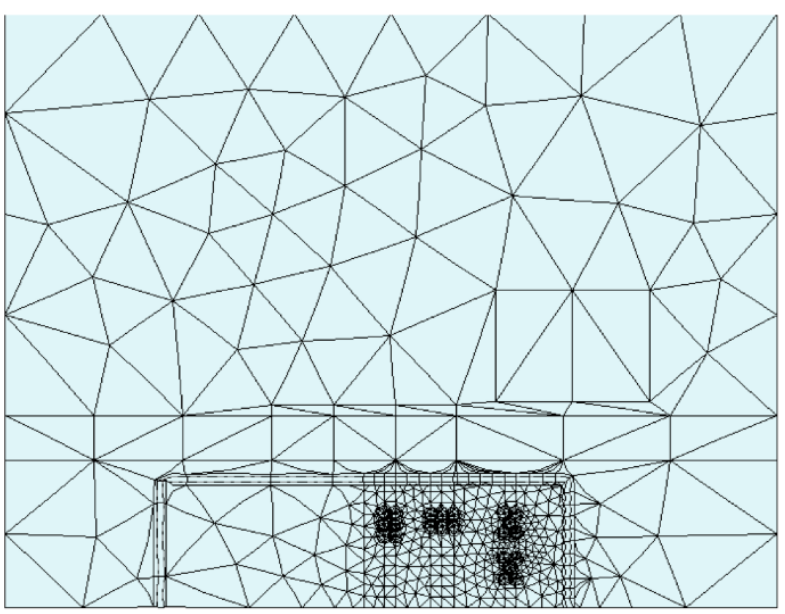

a) $2 \mathrm{D}$ mesh

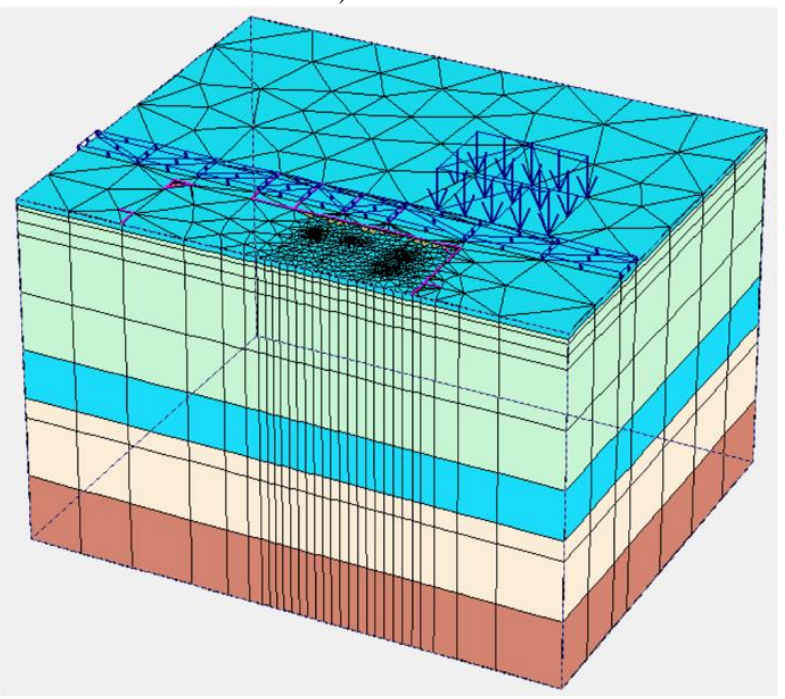

b) 3D mesh

Fig. 8. Elements meshing 2D and 3D of construction in Plaxis 3D foundation model 


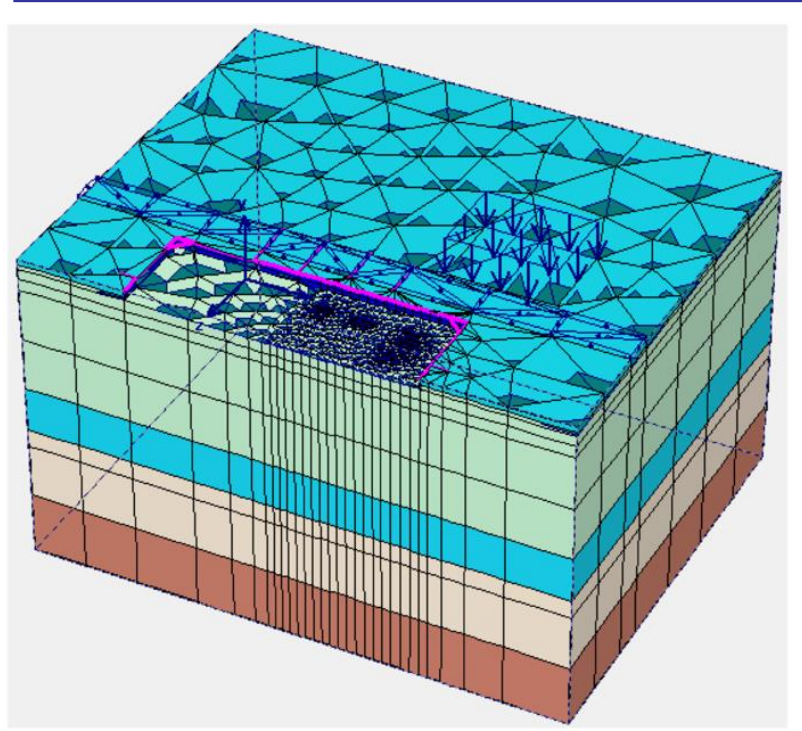

a) Staged construction for the depth of $1.8 \mathrm{~m}$

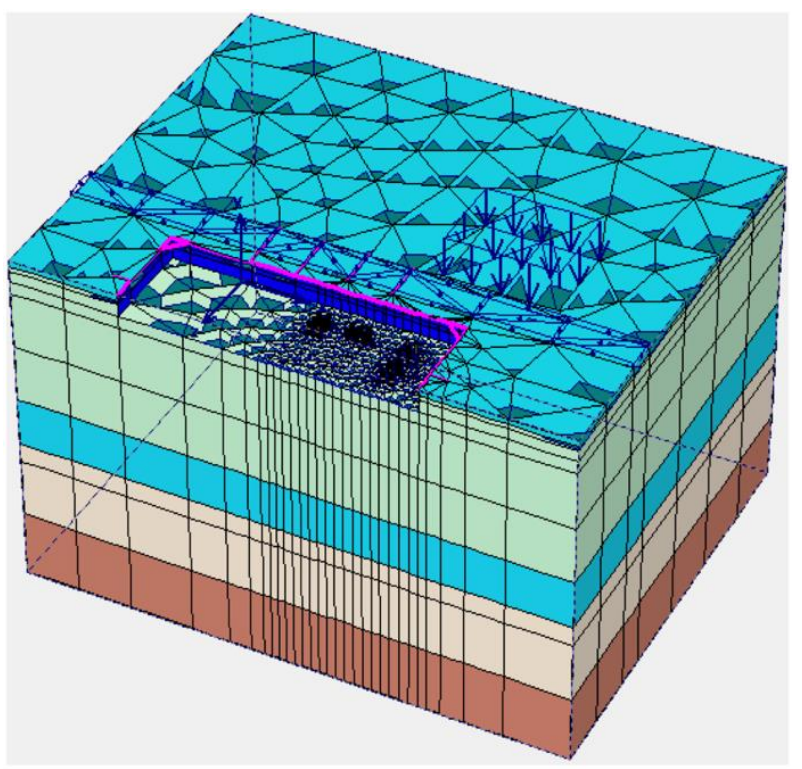

b) Staged construction for the depth of $3.8 \mathrm{~m}$

Fig. 9. Excavation profile for phase of staged construction for the depth of $1.8 \mathrm{~m}$ and $3.8 \mathrm{~m}$ (compared with the natural ground surface)

\section{Results and Discussion}

In actual field, the most leaning pile location is shown in Fig. 10. In this section, the author analyse the movement, cracking reason of the group of piles and compared with the slight deformation PIT of experimental result table in field.

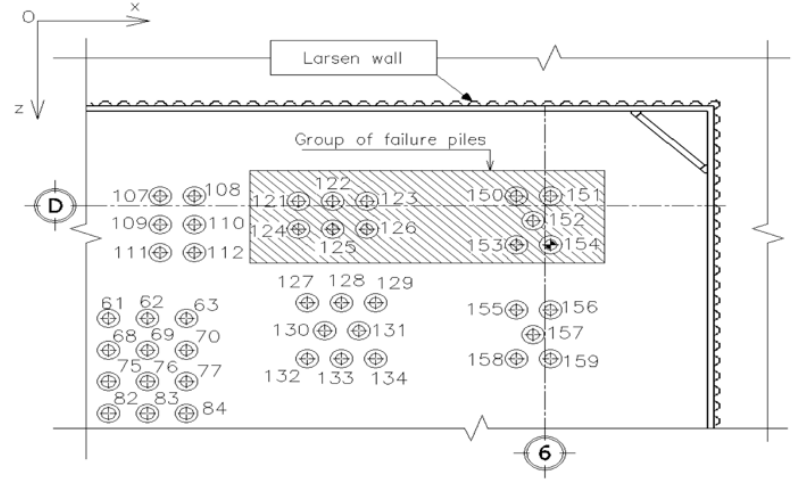

Fig. 10. Group of failure piles plan
From the calculate of Plaxis 3D Foundation under Hardening Soil, the author draws the biggest displacement of piles chart on excavation staged construction (Fig. 11). At 1st excavation stage (depth of $1.8 \mathrm{~m}$ compared with ground surface), the small movement piles fluctuate gently and the largest displacement position is near the Larsen pile. However, at $2 \mathrm{nd}$ stage, the large near by soil mass $\left(70 \mathrm{kN} / \mathrm{m}^{2}\right)$ causes a huge displacement on the group of piles near the wall, the displacement decreased gradually from head to bottom of pile. The largest movement are piles number 121 , 122,123 and 150, which have value in turn are $61.2 \mathrm{~cm}$; $59 \mathrm{~cm} ; 60.1 \mathrm{~cm}$ and $57.9 \mathrm{~cm}$. The rest of piles range from 31,6 $\mathrm{cm}$ to $50.5 \mathrm{~cm}$.

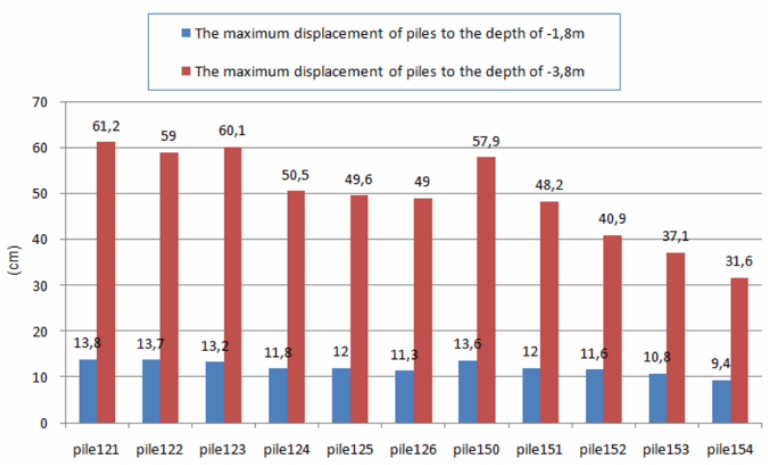

Figure 11. The chart of largest displacement of piles under excavation staged construction $(\mathrm{cm})$

During construction of excavation, the behavior of piles is also compared with the pile craking resistance moment $\mathbf{M}_{\mathrm{cr}}$ $=166.8 \mathrm{kN} \cdot \mathrm{m}$, when bending moment inside the pile exceed this value, pile is considered craking. If the pile reaches $80 \%$ $\mathrm{M}_{\mathrm{cr}}$, pill is assumed to reach the limited state. The largest bending moment inside the pile under the excavation construction is shown in Fig. 12 and the result compared with Table II.

The bending moment of piles in Plaxis 3D Foundation stimulation gives $80 \%$ greater cracked moment, it will lead to cracking. The results are also compared with the result of homogeneity of piles in field by Pile Intergrity Test.

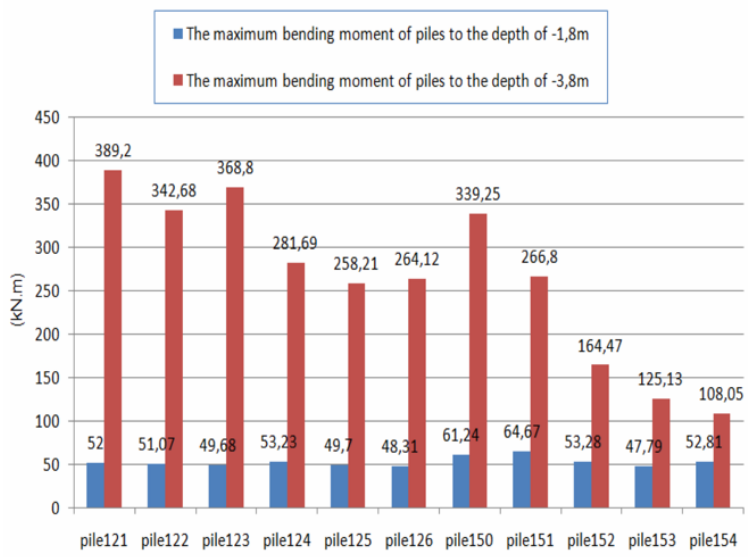

Figure 12. The maximum bending moment of piles in excavation staged construction chart (kN.m)

Choosing the line of pile as Fig. 13 (have large displacement and observation result of field displacement) for analysis. 
TABLE II THE COMPARISON BETWEEN PLAXIS 3D FOUDANTION RESULT AND PIT RESULT

\begin{tabular}{|c|c|c|}
\hline \multirow{2}{*}{ Pile No. } & \multicolumn{2}{|c|}{ Pile condition } \\
\cline { 2 - 3 } & $\begin{array}{c}\text { PLAXIS 3D } \\
\text { Foundation result }\end{array}$ & PIT result \\
\hline 121 & Cracked & Cracked \\
\hline 122 & Cracked & Good \\
\hline 123 & Cracked & Cracked \\
\hline 124 & Cracked & Good \\
\hline 125 & Cracked & Good \\
\hline 126 & Cracked & Good \\
\hline 150 & Cracked & Cracked \\
\hline 151 & Cracked & Cracked \\
\hline 152 & Cracked & Cracked \\
\hline 153 & $\begin{array}{c}80 \% \text { of cracking } \\
\text { moment - critical }\end{array}$ & Cracked \\
\hline 154 & Critical & Cracked \\
\hline
\end{tabular}

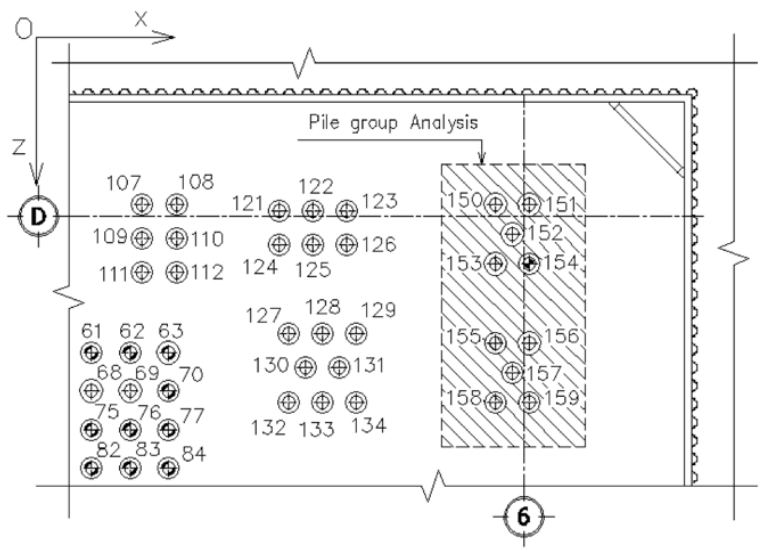

Figure 13. Plan of pile line for analysis

TABLE III. OBSERVATION PARAMETERS OF PILES GROUP

\begin{tabular}{|c|c|}
\hline Pile No. & $\begin{array}{c}\text { Observation displacement } \\
(\mathbf{c m})\end{array}$ \\
\hline 150 & 155,7 \\
\hline 151 & 148,3 \\
\hline 153 & 74,5 \\
\hline 154 & 71,3 \\
\hline 155 & 26,5 \\
\hline 156 & 19,4 \\
\hline 158 & 13,7 \\
\hline 159 & 18,5 \\
\hline
\end{tabular}

The group of piles numbered 150, 151, 153, 154 are great observable displacement becaue actually this piles group were cracked and pushed out, while stimulating by Plaxis 3D, the piles material is linear elasticity so they were not failure and keep the displacement status. Therefore, we not choose piles group of $150,151,153,154$ for analysis because of incorrect result, we choose piles group of $155,156,158,159$ instead.

From the table III, we draw the the chart of horizontal displacement of piles line $(155,156,158,159)$ for each stage construction.

When the 1st stage constructed (depth of $1,8 \mathrm{~m}$ compared with ground surface), we found that the horizontal movement of piles were quite small, fluctuated from $7.4 \mathrm{~cm}$ to $8.4 \mathrm{~cm}$ and the more piles far away from Larsen wall, the more displacement value decreased. The piles above have the largest displacement at the height of $1.8 \mathrm{~m}$ compared with the ground surface, that is also the peak high of the pile. At this stage, we do not consider the observation in field. On the other hand, not the same as 1st stage, at 2nd stage (constructed to $3.8 \mathrm{~m}$ - compared with the ground surface) we saw that piles have large horizontal displacement, and the largest movement of piles are all at the head of piles. The displacement value with observation value at the height of $3.8 \mathrm{~m}$ for each pile is: pile $155(22.9 \mathrm{~cm}$ displacement -26.5 $\mathrm{cm}$ observation), pile $156(22.5 \mathrm{~cm}$ displacement $-19.4 \mathrm{~cm}$ observation), pile $158(21.6 \mathrm{~cm}$ displacement $-13.7 \mathrm{~cm}$ observation), pile $159(22.9 \mathrm{~cm}$ displacement $-18.5 \mathrm{~cm}$ observation). The largest displacement value of the piles line is analysed compared with obsvervation result are quite similar.

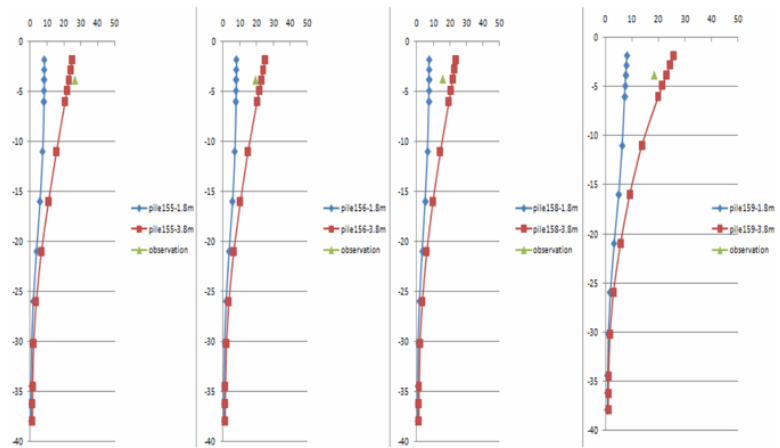

Figure 14. The chart represents the horizontal displacement of wall to depth with two excavation staged construction.

As movement, pile moment near the wall have the greatest value, the more pile far from wall the more moment value of pile decrease: the pile moment away from wall with the distance of $4.547 \mathrm{~m}$ and $7.147 \mathrm{~m}$ (with the pile 150 and 153) have the alternately moment: $339.3 \mathrm{kN} \cdot \mathrm{m}$ and $125 \mathrm{kN} \cdot \mathrm{m}$. With this result, the maximum bending moment exceeded the cracking resistance moment of pile $\left(\mathrm{M}_{\mathrm{cr}}=166 \mathrm{kN} \cdot \mathrm{m}\right)$ appropriated with the homongenerous experimental result of piles in field.

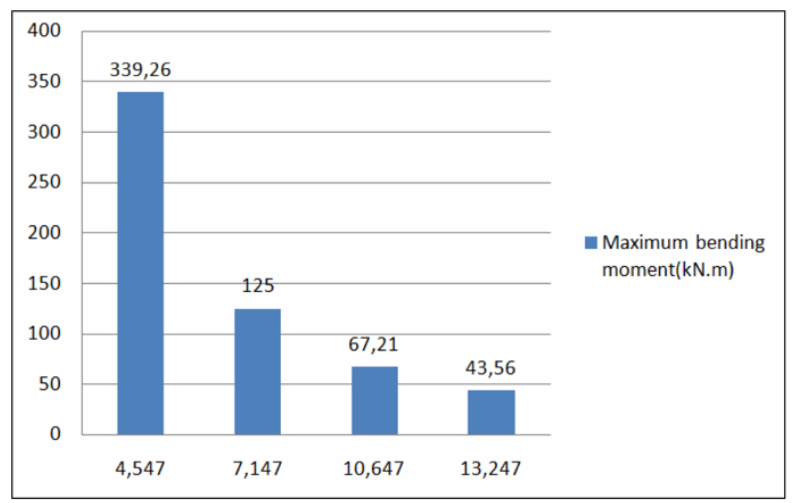

Fig. 15. The chart of maximum bending moment with the distance from piles to wall.

\section{CONCLUSION}

When using the input number as Table I to stimulate by PLAXIS 3D Foundation on Hardening Soil produced the result of horizontal displacement and bending moment of pile approximated the observation value in field, so the input numbers are appropriate. The $\mathrm{E}_{\text {ref }}$ of clay layers were chosen as $\alpha$ equal from 200 to 400 (with $E_{50}{ }^{\text {ref }}=\alpha s_{u}$ ). Thereby, we can analyze the reason piles group in buildings were failure and used this parameter for expanding the analysis to other situations.

For the thick weak soil (clay loam) with the impact of large embankment load $\left(70 \mathrm{kN} / \mathrm{m}^{2}\right)$ far from pit $10.5 \mathrm{~m}$ and 
the load due to construction machine and near by construction $\left(10 \mathrm{kN} / \mathrm{m}^{2}\right)$ away from the edge of excavation $2.6 \mathrm{~m}$ leaded to large bending moment displacement inside pile, exceeded bending resistance moment of pile and caused pile failure.

\section{REFERENCES}

[1] Kok. S.T., Bujang. B.K.H., Jamoloddin. N., Mohd. Saleh, J., and Gue. S.S., "Modeling of Passive Piles - An Overview. Electonic Journal of Geotechnical Engineering", vol. 14, 2009.

[2] G Poulos, LT Chen., "Piles response due to unsupported excavationinduced lateral soil movement", Canadian geotechnical journal, 1996

[3] Goh, A.T.C, Wong, K.S., The, C.I. and Wen, D., "Pile response adjacent to braced excavation", Journal of Geotechnical and Geoenvironmental Engineering, vol. 129, No. 4, pp. 383-386, 2003.

[4] Kok, S.T., Bujang, B.K.H., Jamoloddin, N., Mohd. Saleh, J., and Gue, S.S., "A case study of passive piles failure in open excavation", DF Journal, vol. 3, No. 2, pp. 50-57, 2009.

[5] Leung, C.E., Ong, D.E.L. and Chow, Y.K., "Pile behaviour due to excavation-induced soil movement in clay II: Collapsed Wall", Journa of Geotechnical and Geoenvironmental Engineering, vol. 132, No. 1 , pp. 45-43, 2006.

[6] Leung, C.F., Chow, Y.K. and Shen R.F., "Behaviour of pile subject to excavation-induced soil movement", Journal of Geotechnical and Geoenvironmental Engineering, vol. 126, No. 11, pp. 947-2000, 2000

[7] Leung, C.F., Lim, J.K., Shen, R.F. and Chow, Y.K., "Behaviour of pile groups subject to excavation-induced soil movement", Journal of Geotechnical and Geoenvironmental Engineering, vol 129, No. 1, pp. $58-65,2003$

[8] Thasnanipan, N., Maung, A.W. and Tanseng, P., "Damages to Piles Associated with Excavation Works in Bangkok Soft Clay", in The Sixth International Conference on Problems of Pile Foundations Building, Russia, September $14-18^{\text {th }}$, 1998

[9] Hung Xuan Hoang, Analysis the effect of deep excavation dip to prestressed high strength concrete piles, Master thesis, Ho Chi Minh City University of Technology, 2011 